\title{
18
}

\section{How Tuna is Shaping Regional Diplomacy}

\section{Transform Aqorau}

\section{Introduction}

This chapter examines how tuna has shaped regional politics and influenced the relationship between the Pacific Island states and two of the world's largest trading blocs, the United States and the European Union (EU). This relationship has come under stress in recent years because of the development of arrangements such as the purse seine Vessel Day Scheme (VDS), ${ }^{1}$ the emergence of regional alliances such as the Parties to the Nauru Agreement (PNA) grouping of countries, and because of the strong desire of the Pacific Island states to control their tuna fisheries and maximise their share of the economic benefits flowing from the exploitation of their tuna resources.

The geopolitical underpinnings of the region's tuna management provide an interesting backdrop to this analysis. All of the world's major trading states are involved in this fishery - Japan, Korea, the United States, the EU, and China. Japan has the longest presence in the region's tuna fishery. More recently, China has become a major force in the longline fishery. The region's tuna

\footnotetext{
1 The VDS is a management measure that sets a limit on the number of days purse seine vessels are allowed to fish in the waters of the Parties to the Nauru Agreement (PNA) group of countries and Tokelau. The days are allocated to each party, who then charge fishing companies/vessels for each day they fish.
} 
resources have become a key focal point for the prosecution of the strategic geopolitical interests of these powers. Access to the region's tuna resources allows them a physical presence over a large geographic area of the Pacific, from which they can pursue their strategic interests. The analysis presented here, however, focuses on fisheries relations between the Pacific Island states, the United States and the EU.

This chapter argues that there is a multiplicity of strategic interests that underlie the management of the region's tuna resources. These are often inimical to the interests of the Pacific Island states who want secured rights to their tuna resources. However, it is often assumed that this leads to the Pacific Island states having a shared interest, and that a regional framework fits the strategic and political aspirations of individual states. This is not necessarily the case. It is argued that the regional configuration and architecture has changed, and that Pacific Island states have a diverse range of strategic interests that are not often amenable to a common approach to their relations with external fishing interests.

These differences are manifested not only in Pacific Island states' relations with external fishing states but also their relations with each other. They also explain the difficulties in accommodating the interests of Pacific Island states in current negotiations to extend the Treaty on Fisheries with the United States and conclude a Comprehensive Economic Partnership Agreement (CEPA) with the EU. The conclusion is drawn that regional fisheries interests are not homogenous; these interests are not necessarily shared, and these differences have informed the evolution of a new Pacific regional tuna architecture that has impacted on the shaping of the relations between the Pacific Island states, the United States, and the EU.

\section{The Heterogeneous Tuna Fishery: Skipjack, albacore, yellowfin, and bigeye}

In order to appreciate the impulses that inform the evolution of fisheries management arrangements in the region, it is necessary to understand the structure and dynamics of the region's tuna fishery.

Tuna is a highly migratory resource. It is found in the Exclusive Economic Zones (EEZs) of all the Pacific Island states. However, the abundance and distribution of the different tuna species is not shared equally amongst the Pacific Islands. The major species of tuna are skipjack (Katsuwonus pelamis), albacore (Thunnus alalunga), yellowfin (Thunnus albacares), and bigeye tuna (Thunnus obsesus). The distribution and abundance of these four species have helped shape the 
cooperative arrangements that have been developed over the past 30 years. Skipjack, for instance, is found mainly in the equatorial waters of the Federated States of Micronesia, Kiribati, Marshall Islands, Nauru, Palau, Papua New Guinea (PNG), Solomon Islands, Tuvalu, and Tokelau. These countries are colloquially known as the Nauru Group. They have used their common interest in skipjack, which is targeted by purse seiners, to establish their own regional arrangements. Albacore tuna tend to be caught further south in subtropical and temperate waters. This fishery is confined to the waters of countries such as the Cook Islands, French Polynesia, Samoa, Tonga, Fiji, Vanuatu, New Caledonia, New Zealand, and Niue. There is also a sizable albacore fishery in Solomon Islands, PNG, Tuvalu and the Southern Gilberts, who are members of the Nauru Group.

The countries where albacore dominates their fishery have formed the Tokelau Arrangement - a coalition to advocate limits for albacore fishing and to maximise economic returns from albacore tuna. There is cross membership within these different groups by countries such as Tuvalu and Solomon Islands, who are members of both the Nauru Group and the Tokelau Arrangement, reflecting the different fisheries in their waters. Albacore tuna also provides the backdrop for another species aligned coalition, the Te Vaka Moana Group, which consists of Samoa, Tonga, Niue, Tokelau, Cook Islands, New Zealand, and Tokelau. This is a New Zealand inspired and funded Polynesian group formed around shared interests in albacore tuna; but it is also motivated by a shared desire among these countries to cushion the growing influence of the Nauru Group. That leaves bigeye and yellowfin tuna, which is a bycatch in the skipjack fisheries within the Nauru Group of countries, and to a lesser extent in the albacore fishery in the southern Pacific Islands countries, but which is also a core target species in the tropical longline fishery which occurs mainly in the high seas areas, often adjacent to the EEZs of the Nauru Group

There is also the Melanesian Spearhead Group (MSG) Fisheries Committee. This is not a species-focused group, but is aligned around the common trade interests of the Melanesia countries of PNG, Solomon Islands, Fiji, Vanuatu, and the Kanak Independence Movement of New Caledonia. In the main, the MSG have explored issues in which they can maximise their involvement in the value chain in the various fisheries, including coastal fisheries. This transcends both the longline and purse seine fishery. These sub-regional coalitions and alliances have been built around a variety of factors, including the geographic range of different stocks, the fishery that targets these stocks, and cultural ethnicity (in the case of Te Vaka Moana and MSG Fisheries Committee). The effectiveness and success of these various groups have varied. While the MSG represents the largest demographic group in the region, its fisheries committee is yet to make any impact, perhaps reflecting the fact that alliances are better drawn around fishing interests. Similarly, the Te Vaka Moana's influence has been minimal. 
Some of these alliances are based around policy coordination, advice generation, and a forum whereby allocations are set. The efficacy and effectiveness of these alliances are dependent on their architecture. Unlike the skipjack Nauru Group-affiliated arrangements, the other alliances do not have legally binding decision-making regimes, and to some extent this has influenced their efficacy in shaping regional tuna politics, in particular, the extent to which they can leverage influence.

It is instructive to note that these alliances work within two overarching political frameworks, namely the Pacific Islands Forum Fisheries Agency (FFA) and the Western and Central Pacific Fisheries Commission (WCPFC). The FFA is a coalition embodying all the Pacific Island states but its core functions are to coordinate policy advice and provide technical support to the Pacific Island countries. It does not manage tuna. The WCPFC is a body initiated by Pacific Island Forum leaders to bring compatible governance into high seas areas through the establishment of conservation and management measures for tuna inside and outside the EEZ, although EEZ measures are applied and adopted by the Pacific Island countries pursuant to their sovereign rights. Its membership includes the FFA member countries and the major fishing states: France, the EU, China, Japan, Taiwan, Indonesia, Philippines, Korea, Canada, and the United States. It is probably best described as a coalition of the unwilling, as it provides a forum whereby stakeholders unwillingly cooperate with one another. Both organisations provide an effective forum for discussions.

There are serious limits to the effectiveness of the WCPFC. While it has been successful in adopting conservation measures for seabirds and sharks, it has been less successful in adopting effective measures for bigeye tuna, which is currently subject to overfishing. This is attributable to different interests in the organisation which make it difficult to arrive at mutually acceptable outcomes. The tuna measures adopted by the WCFC have evolved from PNA initiatives, underscoring the role that sub-regional arrangements play in ensuring the WCPFC discharges its obligations.

The vacuum that has been created by the WCPFC's failure to provide an effective forum for management of the target tuna species is being filled by PNA countries. The influence of the powerful PNA bloc hinges on the leverage that it is able to apply through access to member country EEZs. This may be explained in part by the catch statistics illustrated in Figure 18.1, which shows the catches of four key species. In 2013, 2.62 million metric tonnes (mt) of tuna was caught in the Western and Central Pacific Ocean (WCPO). Of this, the purse seine catch accounted for 1.9 million $\mathrm{mt}$, of which skipjack tuna was 1.8 million $\mathrm{mt}$, bigeye tuna 150,000 $\mathrm{mt}$, yellowfin 524,000 mt, and albacore tuna $143,000 \mathrm{mt}$. About 68 per cent of the skipjack catch is taken from the waters 
of the PNA waters. This is important, because the proportion and size of the skipjack tuna that is taken from the PNA gives them influence, which they have been able to leverage against fishing states and the other Pacific Island countries.

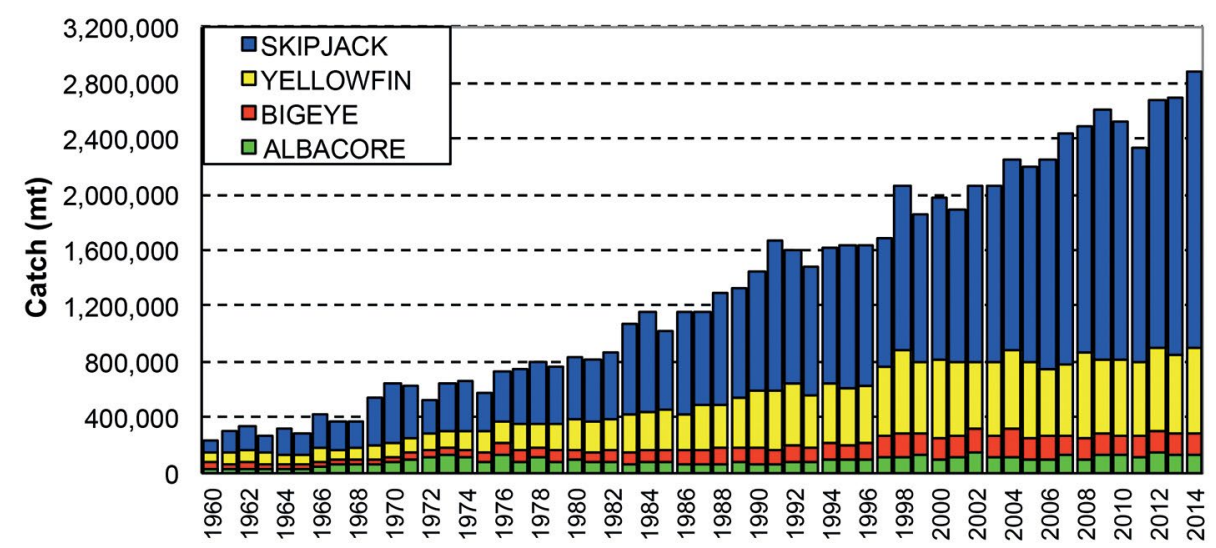

Figure 18.1: Total tuna catch WCPO

Source: SPC, Noumea, 2015.

Figure 18.2 illustrates the proportion of catch by gear type. As discussed above, some of the alliances formed in the region are related primarily to the predominance of gear. Catch by gear is thus dominated by purse seine vessels, which are the largest fishery in terms of value and volume of catch, followed by longline, pole and line, and others, such as trolling and handlines. It should be noted that this data also includes Indonesia and the Philippines.

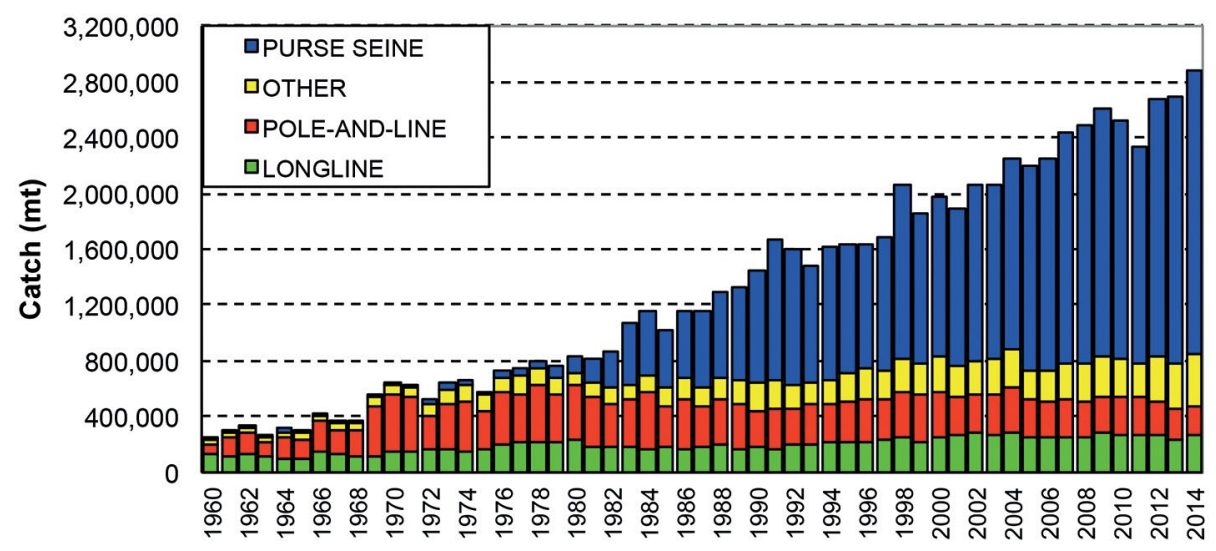

Figure 18.2: Total tuna catch by gear

Source: SPC, Noumea, 2015. 
The differences that have emerged in regional tuna diplomacy since the 1976 forum declaration on the Law of the Sea are a function of a variation in commercial interests, and do not necessarily reflect a lack of desire for common action. In the mid-to-late 1970s, when the Pacific Island states were gaining independence, they had a collective and shared interest in the EEZ regime, as extended maritime jurisdiction intertwined with the idea of self-determination. In the 1980s, when the US fleet fished illegally in the region, the Pacific Island states had a common cause: to control US vessels, and support the US in preventing the region's exposure to overtures from the Soviet Union. Thus the Treaty on Fisheries was negotiated. With time, changes in dynamics, the development of fisheries, and more clearly defined fishing rights, the interests of Pacific Island states have diverged and become more narrowly aligned along economic goals based on the different fisheries that occur in their EEZs.

References to a common interest in the tuna fishery by the Pacific Islands states are not entirely accurate. It is argued that those who advocate a common approach to the management of tuna in the Pacific Islands region misunderstand the dynamics at play and the different arrangements that underpin the management of the different stocks. Nowhere are these differences more pronounced than in the negotiations of two regional instruments, the Economic Partnership Agreement (EPA) with the EU and the negotiations to extend the Treaty on Fisheries with the United States.

\section{The Treaty on Fisheries between the Governments of Certain Pacific Island States and the United States}

Differences over the form and shape of the 1987 treaty have emerged in recent years because of its rigid structure, subsidisation from the US government, the failure of US vessels/industry to pay commercial rates for access, and the difficulty of shaping an arrangement that meets all of the stakeholders' interests. These differences have caused friction between the PNA and non-PNA members within the FFA, and between the Pacific Island states and the US government. The treaty was designed to address a major problem with the US position in the 1970s. During the negotiations of the 1982 United Nations Convention on the Law of the Sea, the US did not accept that highly migratory fish stocks such as tuna could fall within the sovereign rights of coastal states. They argued that tuna stocks could only be managed internationally. They enforced this interpretation of the law of the sea through Magnuson Act embargoes, which they applied to any state that arrested US vessels for tuna fishing illegally in their EEZ. Papua New Guinea and Solomon Islands were at the receiving end of US sanctions, which caused friction between the US and the Pacific Island states in the 1980s. 
In order to resolve this issue, the Treaty on Fisheries was concluded in 1987, giving US vessels the right to roam freely throughout the Pacific Islands region and catch tuna in return for a fee. Initially, the licences were valid for a period of five years. The second and third licensing terms were for 10 years, locking in access at a fixed price for 10-year periods. While this provided the US with a stable environment for their vessels to operate in the region, it did not give the Pacific Island states much flexibility. Tensions began to arise when the PNA VDS became fully operational and US fleets were not being subjected to the VDS. These tensions were also exacerbated by the way in which the treaty constrained the ability of the Pacific Island states to amend their national laws. The treaty prohibited the Pacific Island states from adopting national measures if these were in conflict with the treaty. There were various tensions at play. There was tension between the Pacific Island states and the US because of the Pacific Island states' lack of flexibility to apply national laws in their EEZs without US consent if the matter fell within the purview of the treaty. There was tension between the Pacific Island states, with the PNA wanting to see the treaty come under the VDS. The PNA also wanted US industry to pay commercial market rates for their fishing days. The non-PNA countries supported the status quo, as they received a proportion of the share of the treaty funds - which the US government paid for access for its flagged vessels - and did not want to see their share reduced. These issues emerged because the VDS had seen an increase in the value of access from other fleets, but there have not been enough funds from the treaty to ensure that US industry paid a premium for their multiple zone days. This became a source of tension between the PNA and non-PNA countries. These tensions largely reflected the different disparate interest groups discussed above. The treaty is essentially a purse seine arrangement targeting skipjack tuna. Almost all of the efforts of the US fleet occurred in PNA waters, where US industry were in effect paying just ten per cent of the regional benchmark for regional, as opposed to bilateral, access.

The Treaty on Fisheries, once a symbol of regional cooperative success, has become politically divisive, impacting on relations between the US and the Pacific Island states, the PNA and non-PNA members, and within the PNA group itself. The rigid form and shape of the treaty has made it incompatible with a market-based instrument such as VDS, especially where parties are compelled to contribute days to allow US vessels to operate in the region. Although the treaty's design was suitable at the time of its signing in 1987, it has begun to impact on the effectiveness and efficacy of the VDS. It was inevitable that there would be a conflict between stakeholders because of the different interests at stake. These difficulties have been somewhat ameliorated as a result of the willingness of parties to set aside their differences. Whether they have been fully resolved remains to be seen. By June 2013, the treaty had been assimilated under the VDS, but under arrangements in which the PNA were compelled 
to allocate days to the treaty, rather than voluntarily contribute days based on the value of those days. This is a matter of ongoing negotiations with the United States, and is the cause of some friction amongst the Pacific Island states. The PNA have also been interested in reshaping the treaty to deal directly with the US tuna industry, but have been frustrated because the treaty does not allow for access to be individually negotiated as commercial arrangements between the Pacific Island states and US boat owners.

The Treaty on Fisheries has defined the relations between the US and the Pacific Island states, as underscored by Secretary of State Hillary Clinton in her letter to Pacific Island leaders in November 2011:

Over the past quarter century, the treaty has been the cornerstone of the economic and political relationship between our countries. In particular, the treaty has:

- Provided a foundation for active cooperation for the conservation and management of the region's valuable fisheries resources and related issues, including cooperation on fisheries monitoring, surveillance, and enforcement;

- Supported a vital economic and commercial relationship involving the US fishing industry;

- and provided economic benefits to the Pacific Island parties of approximately $\$ 450$ million over the past 25 years.

The importance of this relationship and the framework that the treaty provides for it is not lost on the PNA members and the rest of the Pacific Island states. The weight which they give to this broad political and economic relationship, however, varies. PNA members view fisheries access as commercial arrangements and therefore delink the aid component of the treaty, which is contributed by the US State Department as economic assistance and is the subject of a separate agreement between the US and the FFA, known as the Economic Assistance Agreement. PNA members view US aid and its political and strategic ramifications as being separate from the commercial access that US vessels enjoy in their EEZs. However, it is clear that there will have to be more flexible arrangements for the US industry if there is to be an ongoing relationship between the Pacific Island states and the United States. This will have to be defined around the principles articulated by the PNA members at their meeting with the United States in March 2014. These include:

- PNA and Tokelau recognise the regional and political importance of the treaty and will thus continue to cooperate among themselves in the provision of access for US vessels, which is conditional on meeting the needs of their domestic fleets and maximising benefits from fishing in their waters. 
- There is a range of interests, needs and opportunities among Pacific Island states which must be recognised in any future arrangements for the provision of access for US vessels, including, as appropriate, through bilateral and subregional arrangements.

- The value and competition for access to waters where the VDS applies is continuing to increase. Fees for US vessels will need to meet the market conditions for vessel days in these increasing competitive processes. US vessel owners may have to bid for days.

- Participation in the provision of access for US vessels must be on a voluntary basis, and no party should be pressured to provide access.

The non-PNA members have not agreed to these principles. They have disagreed on the contribution of fishing days to the treaty and the distribution formulae for funds received from the treaty. Even within the PNA, there have been disagreements over the distribution formulae for days that are to be contributed to the treaty. There have been disagreements between the United States and the Pacific Island states over the structure of the treaty. Getting a regional arrangement to fit neatly within the different interests at play has not been easy. Pacific Island states, the PNA in particular, want greater flexibility. This is simply to reflect the range of interests, needs and opportunities among the Pacific Island states. While there are a range of regional and sub-regional interests, the general approach of the Pacific Island states to management of the purse seine fishery is a rights-based approach. These approaches only work when the rights holders are able to use or discharge their rights in an unrestricted way according to their circumstances. As such, their interests, pushed by the PNA, are to provide access opportunities to US vessels in a greater range of forms than in the past.

\section{The Economic Partnership Agreement with the EU}

The negotiation of the CEPA with the EU has brought out differences within the region, which have had implications for the negotiation of a regional trade agreement between the Pacific Island states and the European Union. Developing a regional comprehensive trade arrangement that reflects all the interests of the Pacific Island states has been difficult, especially negotiating an instrument as a single region. While the imbalance in the trade interests between countries such as PNG and Fiji on the one hand, and Niue, Tuvalu, and Kiribati on the other, are obvious, it is the difference in fisheries interests between the PNA, nonPNA, and the EU that have impacted most on negotiations, reflecting the central role of fisheries in the external and internal relations of the Pacific Island states. 
The CEPA purports to establish a trade agreement between the EU and the Pacific Island states in place of the development arrangement known as the Cotonou Agreement. This supersedes the better known Lomé Convention. Negotiation of the new trading arrangements commenced in September 2002 and CEPAs were supposed to enter into force by 1 January 2008. Negotiating as a single region ignores the differences that divide the Pacific Island states. The differences in the fishing and trading interests of the Pacific Island states culminated in a 2007 split by PNG and Fiji, when they initialled the Interim EPA to avoid disruption to market access for their canned tuna and sugar. The Interim EPA was negotiated by the Pacific-African, Caribbean and Pacific (PACP) group but the other Pacific Island states did not initial the Interim EPA on the grounds that it did not address their development needs, insisting instead that all Pacific Island states continue to negotiate a development-friendly CEPA that included tuna.

After the initialling of the Interim EPA, the Pacific Island states and the EU decided to explore opportunities to further develop an agreement leading towards a comprehensive free trade agreement that would contain provisions for investments, services, and intellectual properties.

Differences over the fisheries component of the EPA reflect the different interests of the PNA and the non-PNA countries, and processing and non-processing countries. PNG had secured global sourcing for HS 1604 and HS 1605 fisheries products - cooked and processed products which were of particular interest to the PNA members - in the Interim EPA. However, during CEPA negotiations, some of the Pacific Island states expressed interest in the export of fish pieces in their natural state (HS 0304-0305) and demanded global sourcing opportunities for fresh fish products. In return for this access, the EU expressed interest in re-securing guaranteed access of five per cent of the total fishing effort under the management of the Pacific Island states. Just what five per cent meant and where it might be processed has never been explained, but no investment has been proposed on account of these proposals.

After the Interim EPA was initialled and ratified, the EU Spanish fishing interests started lobbying against the global sourcing given to PNG and Fiji in the Interim EPA. This resulted in the EU parliament setting up a committee on fisheries to evaluate and research the negotiations and preferences offered to the EU under various trade agreements. Reports given to the EU parliament, such as the 2013 Fraga Report, were blatantly misinformed and misguided, and intended to portray a negative slant on the management of the tuna fisheries by the PNA member countries. 
The non-PNA members wanted the PNA members to sacrifice their fisheries development and management interests in return for a trade agreement with the EU at any cost. The EU further demanded oversight of PNA governance and endorsement of rejected EU proposals at WCPFC level. Additionally, the EU demanded the reopening of the global sourcing provisions of the Interim EPA.

The PNA were concerned about sacrificing fishing opportunities for surface fisheries in exchange for global access for fresh fisheries - products that studies have suggested may only provide seasonal opportunity at best and are not accessible because only three PACP countries currently have EU recognised competent authorities, which, even if fully domestic, would be eligible under rules of origin without global sourcing. The PNA members were concerned about the EU's approach to tuna fisheries in the region not only because of their poor track record of conservation in other oceans, but they were now seen to be using the CEPA negotiations to manage the region's tuna resources.

The differences between those that want access to the EU market at any costs and those, such as the PNA, who do not want to sacrifice market access by acceding some of their tuna management and conservation rights to the EU, have exacerbated the complexity of negotiations. Arguably, this merely reflects different national interests that belie the various fisheries that exist within the region. During the negotiations, the EU have openly challenged the Pacific Island state-inspired regional fishery partnership agreements and sovereign rights to manage their EEZs, in favour of a wider accord, 'where any fisheries agreement between the EU and Pacific States shall be concluded taking into account the conservation and management measures of the WCPFC'. In other words, the EU wants to decide how the Pacific Island states should manage their fisheries resources. The PNA viewed the EU as being divisive and cutting a wedge amongst PNA, and between the PNA and the rest of the Pacific Island states. In its Fisheries Partnership Agreement (FPA) with Kiribati, the EU actively sought to undermine the regional management measures advocated by the Pacific Island states, including abuse of the VDS and pursuing a negative conservation agenda of anti-selective fishing against mesh size increases, proFish Aggregating Devices (FADs), and opposition to closed areas. ${ }^{2}$

The introduction of the PNA purse seine VDS represents a global threat to the EU's FPAs. The changing structure of fishing access arrangements, with the VDS creating a seller's market, represents a threat to the EU FPAs. The average

2 The mesh size restrictions relate to the size of mesh in the purse seine nets. The minimum mesh size is intended to ensure that smaller size fish are able to escape after being caught in the nets. FADs are floating objectives that tend to attract other species. Vessels target these because it is easier for them. The problem is that there is a higher proportion of juvenile bigeye tuna, which is already overfished, caught with FADs. The EU have opposed closures of high seas areas in the eastern Pacific areas where the proportion of their catch of bigeye tuna is about 18 per cent, whereas bigeye tuna bycatch on other areas is about 5 per cent. 
returns from the VDS have been about US $\$ 400$ per metric tonnes on catch, which is generally above the EU FPAs. Arguably, the boot is no longer on the foot of the EU as a competitive market for access arrangements. Support for the VDS has meant that the EU has been put on the back foot, consequently it has had to resort to other tactics, such as using the CEPAs to enforce its global domination. Throughout the negotiations of the CEPA, the EU has been seeking to increase its control of the tuna fisheries in the Pacific by putting pressure on the Pacific Island states to allow it to have a say in the way they manage their tuna resources.

Obtaining a regional consensus on this has not been easy. The PNA members believe that the benefits generated from access to the European fresh fish product market are insignificant compared to other markets, and will probably fail to materialise because of the high cost of trade. The price for this small gain in accepting EU fishing access to the Pacific would be the sustainability of the tuna resource and loss of higher rentals, which can be achieved through agreements with friendlier fishing and trading partners.

The difficulties with achieving consensus on these issues reflects the different fisheries that exist in the region, together with the varying levels of development and interests. What is clear is that if the heavy handed approach of the EU extends to all sectors under a CEPA, the Pacific Island states could have less independence than a French territory in the region.

\section{Conclusion}

This chapter examined the emergence of regional arrangements aligned along different tuna stocks, the fishery that targets them, and the influence that these arrangements have had on two key regional negotiations: the renegotiations of the Treaty on Fisheries with the United States and the CEPA with the EU. Some commentators have derided the emergence of sub-regional groups. However, in the context of fisheries, sub-regional groups such as the PNA have had a major influence on regional tuna negotiations and fulfilment of national development goals. Since most of the fishing takes place in their waters, they can dictate the terms and conditions under which access is negotiated. Having a single region arrangement is useful for some purposes, but not for others. It is clear though that single region arrangements are normally determined by the lowest common denominator. This is known as the Niue factor. In single region arrangements where decisions must be made by consensus, a small country such as Niue - with no US fishing in its waters and no trade with the EU - can prevent the best outcomes because their interests also have to be taken into account. The increase in treaty funds from the Treaty on Fisheries - 
from US\$18 million to US\$21 million - was delayed for some years because Niue wanted an increase in shares apportioned as project development funds. Conversely, the increase in treaty payments - from US\$21 million in 2012, to US $\$ 63$ million in 2013, and US\$90 million in 2015 - was driven by the PNA and demonstrates the power of the VDS. It is doubtful that this would have been possible through a single region approach because of the Niue factor. Similarly, if the PNA members were not opposed to global sourcing for fresh fish in return for allowing the European Union a say in how their fisheries are managed, the region would have a trade arrangement in which only the EU could have a direct say in what Pacific Island states do in their own waters.

The complexity of the dynamics in fisheries and the relationships between the Pacific Island states and their external partners is creating new challenges to the way these issues are addressed. The diplomacy of the past, the 'Pacific Way', and doing things by consensus is not going to work because of the complexities of the issues that the Pacific Island states now confront. These challenges raise questions about the efficacy of existing regional architectures, the role of nation states, and the need to explore models of integration that can best deliver outcomes for the various fisheries. The PNA arrangements, in which measures are legally binding and where a common currency is shared amongst VDS membership, might be a model that could be considered by other Pacific Island states. It is imperfect, but it has strengthened the negotiation hands of its members. 
This text is taken from The New Pacific Diplomacy, edited by Greg Fry and Sandra Tarte, published 2015 by ANU Press, The Australian National University, Canberra, Australia. 